\title{
High-Efficiency Grid-Tied Power Conditioning System for Fuel Cell Power Generation
}

\author{
Jong-Kyou Jeong*, Byung-Moon Han ${ }^{\dagger}$, Jun-Young Lee*, and Nam-Sup Choi** \\ $\dagger^{*}$ Dept. of Electrical Engineering, Myongji University, Yongin, Korea \\ ** Div. of Electrical Electronic Communication and Computer Eng., Chonnam National University, Yeosu, Korea
}

\begin{abstract}
This paper proposes a grid-tied power conditioning system for the fuel cell power generation, which consists of a 2-stage DCDC converter and a 3-phase PWM inverter. The 2-stage DC-DC converter boosts the fuel cell stack voltage of 26-48V up to 400V, using a hard-switching boost converter and a high-frequency unregulated LLC resonant converter. The operation of the proposed power conditioning system was verified through simulations with PSCAD/EMTDC software. Based on the simulation results, a laboratory experimental set-up was built with a $1.2 \mathrm{~kW}$ PEM fuel-cell stack to verify the feasibility of hardware implementation. The developed power conditioning system shows a high efficiency of $91 \%$, which is a very positive result for the commercialization.
\end{abstract}

Key Words: DSP (Digital Signal Processor), LLC resonant DC-DC converter, Nernst model, PEM (Proton Exchange Membrane) fuel cell

\section{INTRODUCTION}

A fuel cell is a clean energy source for generating electricity like a solar cell. Many kinds of fuel cells have been developed for supplying electricity to cars and homes. A PEM fuel cell, which has a simple structure and a high power density, is considered to be a promising DC power source for distributed generation and passenger cars. [1]-[3]

A fuel cell stack shows non-linear characteristics in electrical operation due to the polarization phenomena of the electrochemical reaction. The terminal voltage at the rated load drops to half value at no load. Therefore, the DC-DC converter can boost a low terminal voltage up to a high DC voltage. [4]-[6]

Full-bridge converters, push-pull converters, and boost converters have been widely used as a DC-DC converters for fuel cell stacks. The full-bridge converter has the disadvantage of a high switching loss due to its large number of switching units. The push-pull converter has a lower switching loss due to its lower number of switching units, but it has a rather low efficiency of $88 \%$ because it requires a double winding structure on the primary side. The boost converter has a lower switching loss due to its small number of switching units, but it has a lower voltage boosting ratio of 3 to 4 times. Recently, a multistage boost converter without a transformer was developed to obtain a high voltage boosting ratio. However, its efficiency is located between $86 \sim 90 \%$. An isolated boost converter was

Manuscript received Nov. 27, 2010; revised Mar. 21, 2011

Recommended for publication by Associate Editor Woo-Jin Choi.

$\dagger$ Corresponding Author: erichan@mju.ac.kr

Tel: +82-31-335-6563, Fax: +82-31-330-6816, Myongii University

* Dept. of Electrical Engineering, Myongji University, Korea

** Div. of Electrical Electronic Communication and Computer Eng., Chonnam National University, Korea also developed to obtain a high voltage boosting ratio, of which the efficiency is located between $86 \sim 90 \%$. However, it requires large number of switching units and transformers. In order to increase the efficiency and to reduce the number of components, various types of converter have been proposed and are being proposed by many researchers [7]-[11].

This paper proposes a new power conditioning system to interconnect the fuel cell stack with the power grid. The power conditioning system consists of a 2-stage DC-DC converter and a three-phase PWM inverter. The 2-stage DCDC converter consists of a hard-switching boost converter cascaded with an unregulated LLC resonant converter. The operational feasibility of proposed power conditioning system has been confirmed by computer simulations and the feasibility of the hardware implementation has been verified through experimental results with a laboratory prototype.

\section{Proposed System}

Fig. 1 shows the configuration of the proposed power conditioning system including the whole system controller. The power conditioning system for fuel cell power generation requires a high boost-ratio, high efficiency DC-DC converter because fuel cell stacks have a severe voltage variation between the no-load and the full load conditions. In order to satisfy this condition, this paper proposes a new DCDC converter composed of a conventional boost converter and a 2-stage LLC resonant converter with a high-frequency transformer. The proposed converter has a high efficiency because the LLC converter operates in the soft switching mode with resonance even though the boost converter operates in the hard-switching pattern. It has a simple control structure to 
regulate an output voltage of up to $400 \mathrm{~V}$ by controlling the duty ratio of the boost converter. The overall controller for the proposed power conditioning system is divided into the control part for the DC-DC converter and the control part for the grid-tied inverter.

\section{Fuel-Cell Modeling}

In PEM fuel cells hydrogen gas is supplied to the anode through a platinum catalyst to be ionized into a hydrogen proton and an electron. The hydrogen proton moves to the cathode through a solid polymer membrane and is combined with oxygen supplied to the cathode. Through this electrochemical reaction, the fuel cell generates electricity and heat, and water as a by-product.

The ideal fuel cell voltage is the same as the equilibrium voltage represented by the Nernst model which is based on Gip's free energy. The actual fuel cell voltage is represented by the reduction characteristic of the equilibrium voltage due to the polarization phenomenon.

The unit cell voltage of the fuel cell is represented by subtracting three polarization losses from the equilibrium voltage with respect to the exchange current density. The unit cell voltage shows non-linear characteristics and is expressed by equation (1).

$$
E_{\text {cell }}=E_{\text {rev }}-E_{a c t}-E_{c o n}-E_{\text {ohm }}
$$

where, $E_{\text {rev }}$ is the equilibrium voltage, $E_{a c t}$ is the activated polarization loss, $E_{c o n}$ is the concentration polarization loss, and $E_{\text {ohm }}$ is the ohmic polarization loss.

The activated polarization loss, which is due to differences in the reaction speed on the electrode, is represented by equation (2).

where, $i_{o}$ is the exchange current related to the normal and reverse reactions between the electrolyte and the electrode, is represented by equation (3).

The exchange current is dependent on the pressure, the catalyst, the activated energy, and the temperature. If this value is reduced, the activated polarization $E_{a c t}$ is reduced and the output voltage of the fuel cell $E_{\text {cell }}$ is increased. Therefore, the exchange current is a very important parameter in fuel cells.

The concentration polarization loss $E_{c o n}$ is due to gradient differences in the reaction material concentration, which is represented by equation (4). The ohmic polarization loss $E_{\text {ohm }}$, which is composed of the electrolyte resistance, the electrode resistance, and the lead wire resistance, is represented by equation (5).

$$
\begin{gathered}
E_{a c t}=\frac{R T}{\alpha F} \ln \left(\frac{i+i_{\text {loss }}}{i_{o}}\right) \\
i_{o}=i_{o}^{r e f} a_{c} L_{c}\left(\frac{P_{r}}{P_{r}^{r e f}}\right) \exp \left[-\frac{E_{c}}{R T}\left(1-\frac{T}{T_{r e f}}\right)\right] \\
E_{\text {con }}=\frac{R T}{n F} \ln \left(\frac{i_{L}}{i_{L}-i}\right) \\
E_{\text {ohm }}=i R_{i} .
\end{gathered}
$$

As a result, the output voltage characteristics of fuel cells are represented by the above five equations. If all of the parameters described in these equations are known for a specific fuel cell, its output voltage with respect to the output current can be easily analyzed.

Fig. 2 shows output characteristic curves for a unit cell of a typical fuel cell. The actual cell output voltage $E_{c e l l}$ is reduced in a non-linear manner by the three polarization components from the equilibrium voltage.

In an actual fuel cell, many unit cells are connected in series as a stack structure to build up the terminal voltage. Therefore, the voltage and current characteristics of the stack are determined by multiplying the unit cell voltage by the number of cells and multiplying the unit cell current density by the area of a cell.

Fig. 3 shows the output voltage characteristic of a fuel cell stack that is composed of 47 cells. The $y$-axis shows the actual output voltage, while the $\mathrm{x}$-axis shows the fuel cell current. This curve is required to design the DC-DC converter for a fuel cell power conditioning system.

\section{2-STAGE DC-DC CONVERTER}

Fig. 4 shows the configuration of the 2-stage DC-DC converter, which is composed of a hard switching boost converter and a soft switching half-bridge LLC resonant converter. The controller is composed of an output voltage sensor, a boost converter control, and a fixed-duty gate pulse generator. The proposed 2-stage DC-DC converter offers several benefits to reduce the complexity of the controller design and to decrease the size of the resonant converter transformer by a high frequency operation over $100 \mathrm{kHz}$. Since each converter has a separate function, it can be designed at the optimal operating point, which helps to increase the overall efficiency.

The input voltage is determined to be $24 \sim 48 \mathrm{~V}$ by considering the output voltage characteristic of the fuel cell. This voltage is boosted up to $80 \mathrm{~V}$ by controlling the duty ratio of the boost converter. The half-bridge LLC resonant converter boosts the input voltage of $80 \mathrm{~V}$ up to $400 \mathrm{~V}$ by operating a fixed duty ratio.

The control part of the boost converter compares the reference voltage $400 \mathrm{~V}$ with the measured converter output voltage, and the error signal is passed through the PI control to generate the gate pulse for the boost converter.

When the switch $S_{b}$ of the boost converter is ON, current flows through the reactor $L_{b}$ and energy is charged in the reactor. When the switch $S_{b}$ is OFF, this energy is discharged into the capacitor $C_{b}$ through the diode $D_{b}$.

Fig. 5 shows the four operation modes of the LLC resonant converter, which is composed of two MOSFET switches, a resonant capacitor $C_{r}$, the leakage inductance of the transformer $L_{r}$ and the magnetizing inductance $L_{m}$. The secondary side of the transformer is connected to the full-bridge diode rectifier.

Fig. 6 shows the voltage and current waveforms at each component of the LLC resonant converter. The converter operation can be divided into four modes according to the time interval.

- Operation Mode $1\left(t_{0}-t_{1}\right)$ 


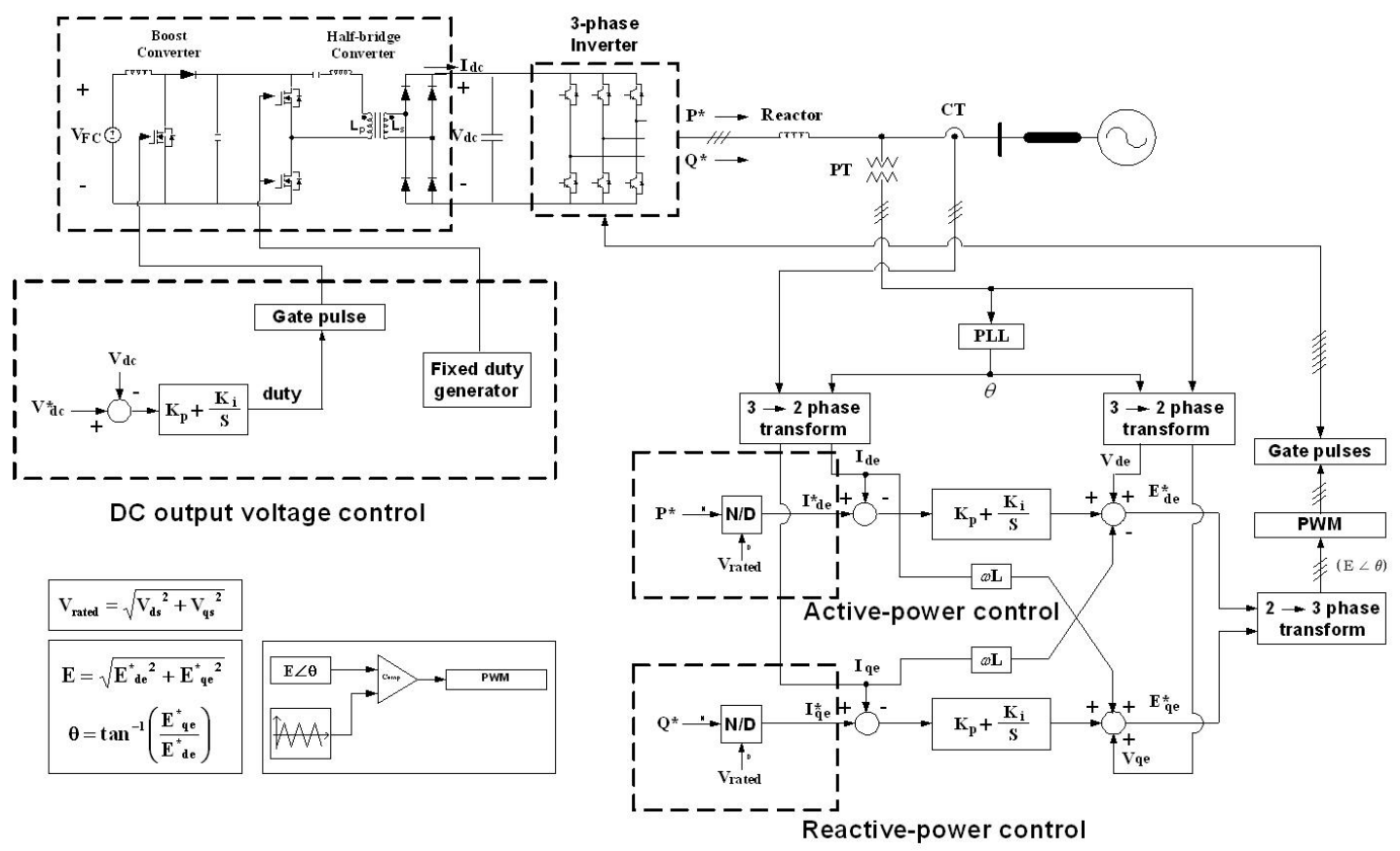

Fig. 1. Configuration of Proposed System.

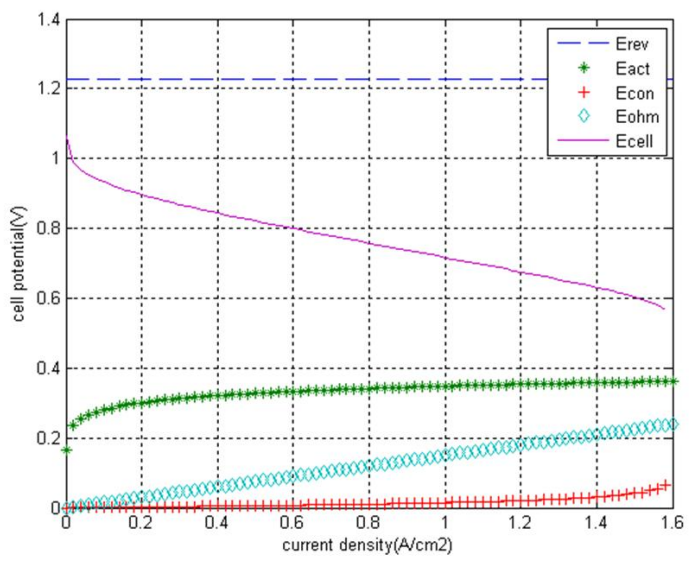

Fig. 2. Output voltage characteristic of Fuel-cell.

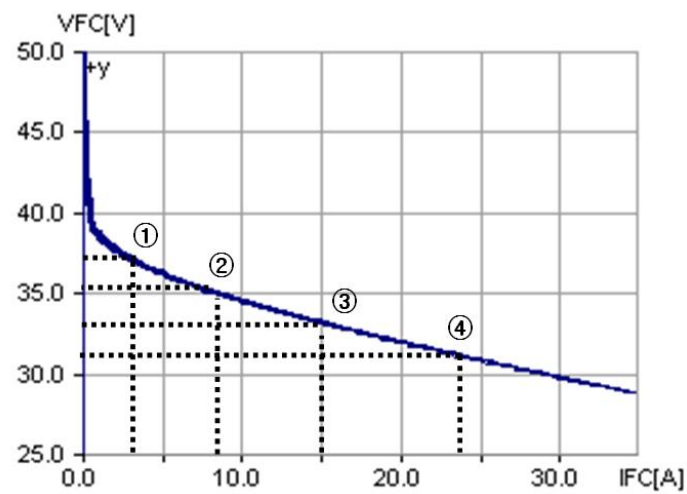

Fig. 3. Output characteristics modeling of fuel cell stack.

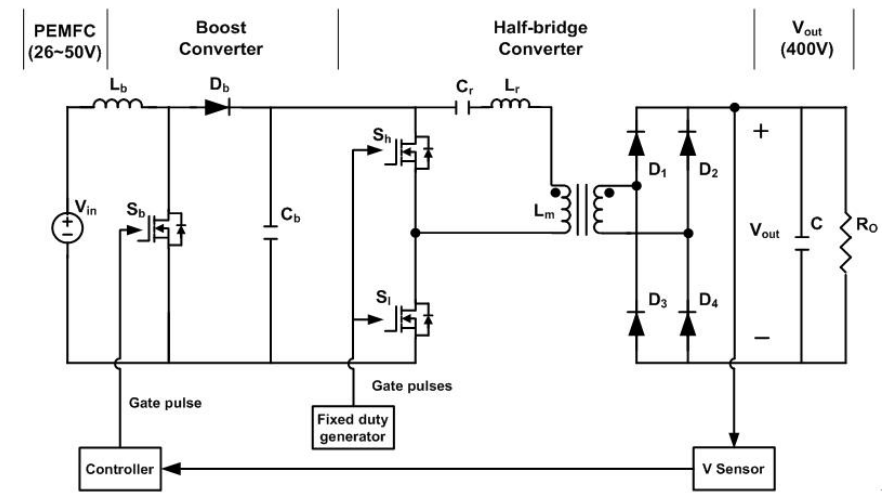

Fig. 4. Circuit Diagram of 2-stage DC-DC Converter.

Fig. 5(a) shows the operation mode in the powering section, which starts at the instant when the MOSFET $S_{l}$ turns on. The resonant current flows through MOSFET $S_{l}$ and the energy is transferred to the secondary side of the transformer. The resonant capacitor $C_{r}$ is charged and the resonant frequency $f_{r}$ is determined by equation (6), because the magnetizing inductance $L_{m}$ does not involve in resonance.

$$
f_{r}=\frac{1}{2 \pi \sqrt{L_{r} C_{r}}} .
$$

On the secondary side, diodes $D_{1}$ and $D_{4}$ are conducting and the current through the magnetizing inductance $L_{m}$ is linearly increased.

- Operation Mode $2\left(t_{1}-t_{2}\right)$

Fig. 5(b) shows the operation mode in the dead time section, which starts at the instant when the switch $S_{l}$ turns off. The current that in used to flow through the switch $S_{l}$ flows through the diode inside the switch $S_{h}$. This allows the zerovoltage switching condition at the switch $S_{h}$. In this section the magnetizing current does not increase any more, and the 
TABLE I

CirCuit PARAMETERS FOR 2-STAGE DC-DC CONVERTER

\begin{tabular}{|c|c|}
\hline Input Voltage & $25 \sim 50[\mathrm{~V}]$ \\
\hline Output Voltage & $400[\mathrm{~V}]$ \\
\hline Output Current & $2.5[\mathrm{~A}]$ \\
\hline Switching Frequency & $100[\mathrm{kHz}]$ \\
\hline Resonant Frequency & $100[\mathrm{kHz}]$ \\
\hline Resonant Capacitor & $0.8[\mu \mathrm{F}]$ \\
\hline Resonant Reactor & $2.9[\mu \mathrm{H}]$ \\
\hline
\end{tabular}

energy transfer to the secondary side of the transformer is cut off.

- Operation Mode $3\left(t_{2}-t_{3}\right)$

Fig. 5(c) shows the operation mode in the powering section, which starts at the instant when the switch $S_{h}$ turns on. The energy that is charged in $C_{r}$ is transferred to the secondary side of the transformer. On the secondary side, diodes $D_{2}$ and $D_{3}$ are conducting, and the current through the magnetizing inductance $L_{m}$ is linearly decreased.

- Operation Mode $4\left(t_{3}-t_{4}\right)$

Fig. 5(d) shows the operation mode in the dead time section, which starts at the instant when the switch $S_{h}$ turns off. The current that in used to flow through the switch $S_{h}$ flows through the diode inside the switch $S_{l}$. This allows the zerovoltage switching condition at the switch $S_{l}$. In this section the magnetizing current does not increase any more, and the energy transfer to the secondary side of the transformer is cut off.

The switching frequency of the LLC converter $f_{s L}$ is selected to be same as the resonant frequency $f_{r}$ calculated to reduce the switching loss. The output voltage can be represented by the following equation:

$$
\frac{V_{o}}{V_{\text {in }}}=\frac{V_{b}}{V_{\text {in }}} \cdot \frac{V_{o}}{V_{b}}=\frac{1}{(1-D)} \cdot \frac{n}{2}
$$

where, $D$ means the duty-ratio of the boost converter.

These four operation modes are sequentially repeated according to the switching frequency of $100 \mathrm{kHz}$. Although the switching frequency is rather high, the switching loss is quite small due to the zero-voltage switching scheme.

A hardware prototype of the proposed DC-DC converter was built and tested to verify the application feasibility for fuel cell power generation. The circuit parameters are shown in Table I.

Fig. 7 shows a picture of the proposed DC-DC converter which was built in the lab. The physical size of the DC-DC converter is $150 \mathrm{~mm} \times 150 \mathrm{~mm}$.

Fig. 8 shows the drain-source voltage across each MOSFET in the LLC resonant converter, and the resonant current through the primary winding of the transformer. The switching frequency is fixed at $100 \mathrm{kHz}$, and the $\mathrm{LC}$ resonant frequency is also fixed at $100 \mathrm{kHz}$. Through experimental results, it is confirmed that the resonant LLC converter operates properly.

\section{Device Loss Analysis for Link Voltage SELECTION}

To select an optimal link voltage, it is necessary to derive a relationship between the link voltage and all of the device losses. To make a guideline to select the link voltage, only the semiconductor device losses will be considered because the

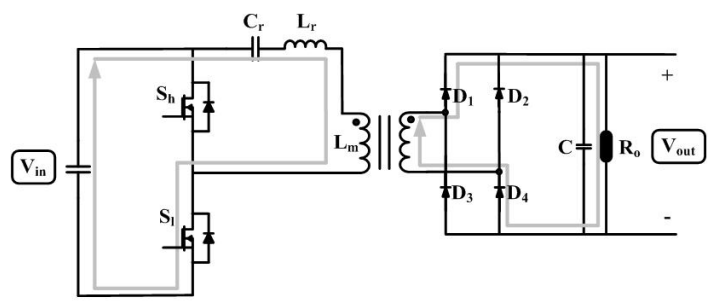

(a) mode 1 .

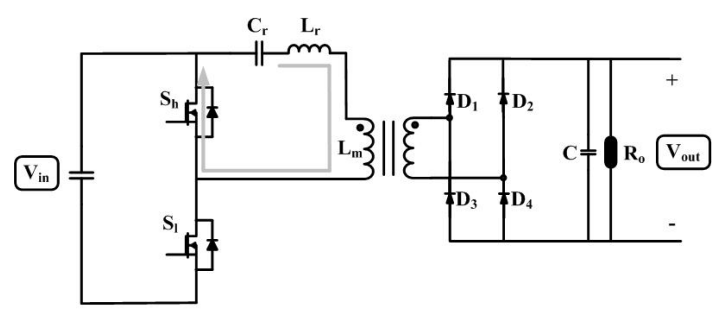

(b) mode 2 .

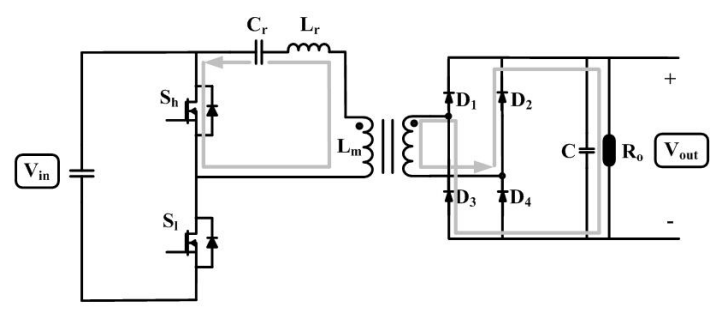

(c) mode 3 .

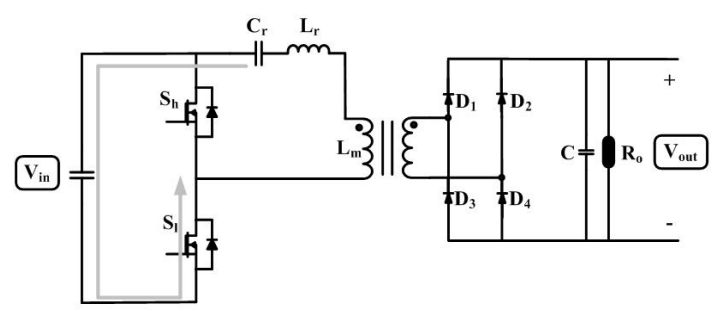

(d) mode 4 .

Fig. 5. Operation of LLC Resonant Converter.

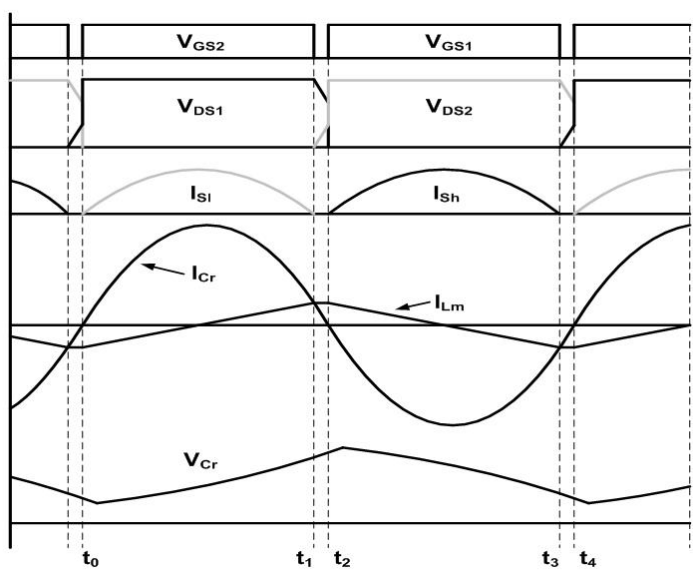

Fig. 6. Operation analysis of LLC Resonant Converter. 


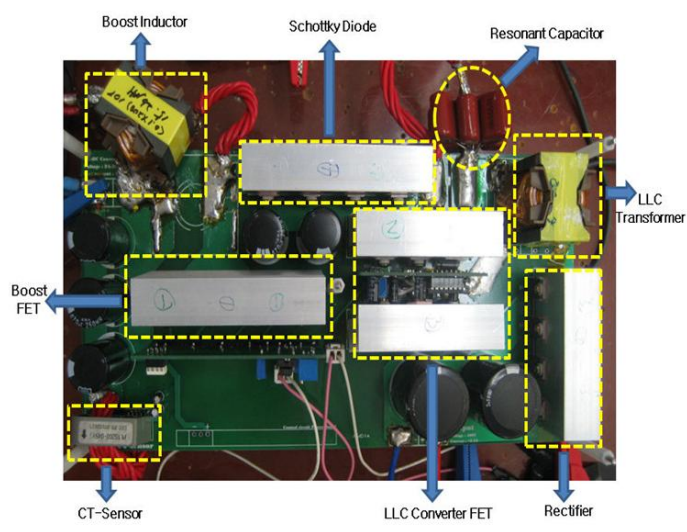

Fig. 7. Picture of proposed DC-DC converter.

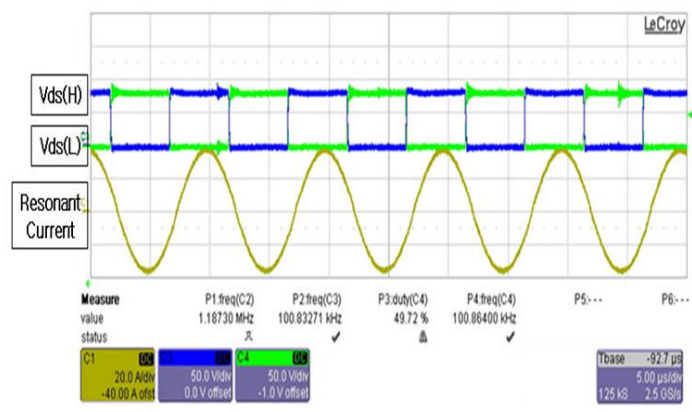

Fig. 8. Drain-source voltage and resonant current of LLC converter.

magnetic element losses become constant if the parameters such as flux swing, wire current density, core material and operational frequency are designed to be identical according to the link voltages. The semiconductor device loss equations can be obtained through the loss analysis of each stage and the procedure is as follows:

- Boost stage loss analysis

Assuming that the boost inductor is large enough to be a current source, the model and its switching waveforms can be depicted as in Fig. 9. After the gate is charged to the threshold voltage $V_{t h}$ the MOSFET $M_{1}$ is ready to carry current and the gate voltage is rising from $V_{t h}$ to the Miller plateau level $V_{g s, m i l l e r}$. This is the linear operation level because $M_{1}$ operates under the pinch-off state. This state continues until $V_{d s 1}$ reaches $0 \mathrm{~V}$. During this interval, all of the boost inductor current flows through $M_{1}$ because the output diode $D_{1}$ changes to the off-state. If the base resistor $R_{g}$ is small enough for the gate drive transistor to be operated in the saturation region, the turn-on gate current $I_{g, o n}$ can be written as:

$$
I_{g, \text { on }}=\frac{V_{C C}-V_{C E, \text { sat }}-V_{g s, \text { miller }}}{R_{g}}
$$

where $V_{C E \text {,sat }}$ is the collector-emitter saturation voltage of the NPN transistor $Q_{1}$ and $V_{C C}$ is the gate drive voltage. $V_{g s, \text { miller }}$ can be obtained from the transfer characteristics of $M_{1}$ and a method is explained to calculate $V_{g s, \text { miller }}$ from the $I_{D}-V_{g s}$ curves of MOSFETs in [13]. The turn-on gate current determines the turn-on time of $M_{1} T_{o n, B}$ and it can be calculated as:

$$
T_{o n, B}=\frac{Q_{g d}}{I_{g, o n}} .
$$

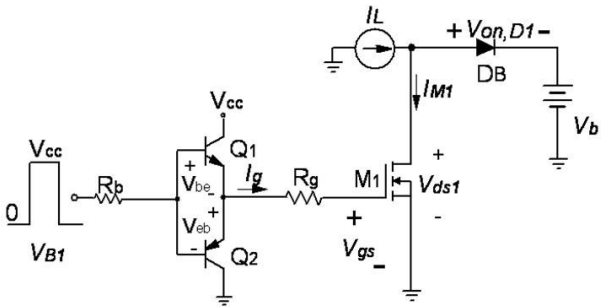

(a)

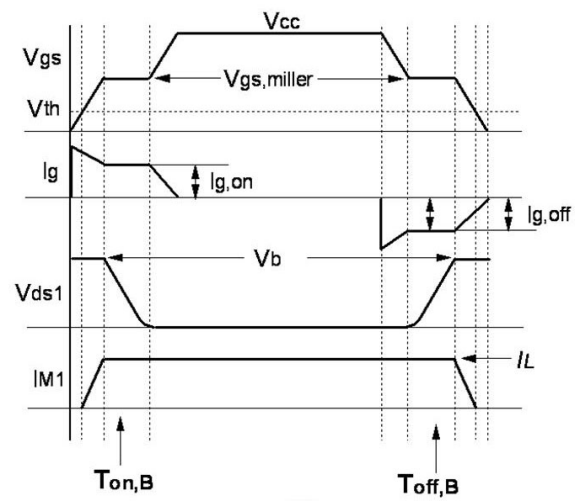

(b)

Fig. 9. Boost converter model(a) and its switching waveform(b) for loss analysis.

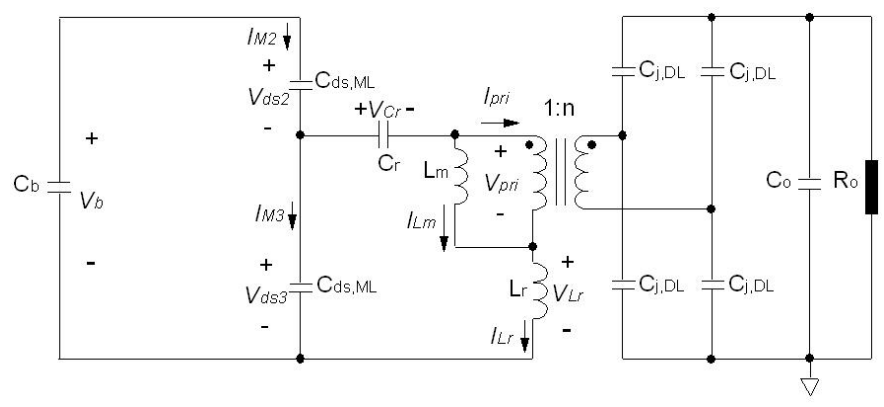

Fig. 10. Equivalent circuit of LLC converter during dead-times.

Thus the turn-on switching loss of the boost converter can be written as follows:

$$
P_{o n, M 1}=\frac{1}{2} I_{L}\left(V_{b}-V_{o n, D 1}\right) T_{o n, B} f_{s B}
$$

where $V_{o n, D 1}$ is the on-drop voltage of $D_{1}$ and $f_{s B}$ is the switching frequency of the boost converter. After $V_{d s 1}$ reaches $0 \mathrm{~V}$, the gate voltage increases to the final gate drive voltage and $M_{1}$ becomes completely turned on.

When the gate-source voltage is discharged to the Miller plateau level, $M_{1}$ enters the linear operation region and the turn-off gate current $I_{g, o f f}$ becomes:

$$
I_{g, o f f}=\frac{V_{E C, \text { sat }}-V_{g s, \text { miller }}}{R_{g}} .
$$

In this equation, $V_{E C, s a t}$ is the emitter-collector saturation voltage of the PNP transistor $Q_{2}$. This current charges the drain-source capacitance of $M_{1}$ and the turn-off time of $M_{1}$ $T_{\text {off }, B}$ is determined as follows:

$$
T_{\text {off }, B}=\frac{Q_{g d}}{I_{g, o f f}} .
$$


TABLE II

LOSS EQUATIONS FOR LINK VOLTAGE SELECTION

\begin{tabular}{lc}
\hline Boost FET loss & Loss equation \\
\hline Boost diode loss & $\frac{1}{2} I_{L}\left(V_{b}-V_{o n, D 1}\right)\left(T_{o n, B}+T_{o f f, B}\right) f_{s B}+C_{d s, M 1} V_{b}^{2} f_{s B}+\left(\frac{P_{o}^{2}}{V_{i n}^{2}} \frac{V_{b}-V_{i n}}{V_{b}}\right) R_{d s, M 1}$ \\
LLC FET loss & $C_{j, D 1} V_{b}^{2} f_{s B}+\frac{P_{o} V_{o n, D 1}}{V_{b}}$ \\
$\frac{1}{3} V_{b}\left(\frac{V_{o}}{4 n L_{m} f_{s L}}-C_{d s, M L} \frac{V_{b}}{T_{o f f, L}}\right) T_{o f f, L} f_{s L}+\left(\frac{2 P_{o}}{V_{b}} \sqrt{\left.\frac{R_{o}^{2}}{32 n^{4} L_{m}^{2} f_{s L}^{2}}+\frac{\pi^{2}}{8}\right)^{2} R_{d s, M L}}\right.$ \\
LLC output rectifier loss \\
\hline
\end{tabular}

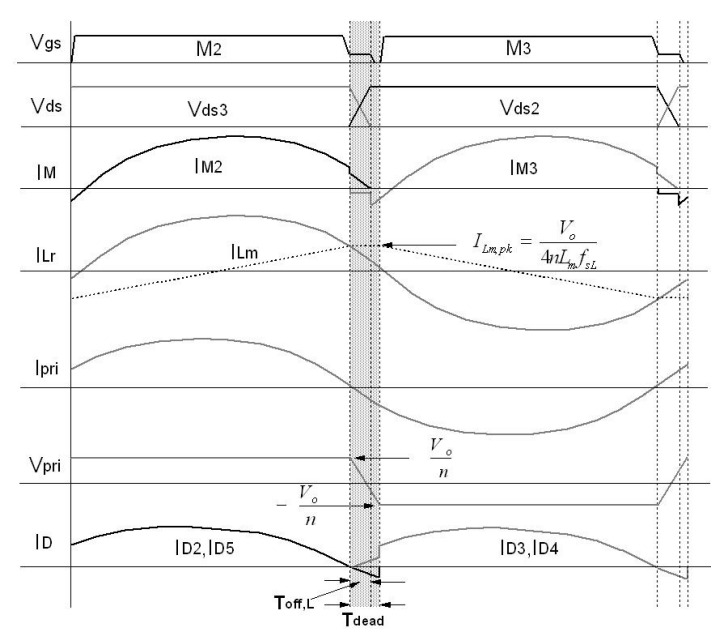

Fig. 11. Switching waveform of the unregulated LLC converter.

Therefore, the turn-off switching loss of the boost converter is:

$$
P_{o f f, M 1}=\frac{1}{2} I_{L}\left(V_{b}-V_{o n, D 1}\right) T_{o f f, B} f_{s B}
$$

Besides theses losses, there is a switching loss due to the drain-source capacitance of $M_{1} C_{d s, M 1}$ and the junction capacitance of $D_{1} C j, D l$, and it can be written as:

$$
P_{C}=\left(C_{d s, M 1}+C_{j, D 1}\right) V_{b}^{2} f_{s B} .
$$

The conduction losses of $M_{1}$ and $D_{1}$ can be calculated using the RMS and the average current carried by them, and they can be calculated as follows:

$$
\begin{gathered}
P_{c o n, M 1}=\left(\frac{P_{o}^{2}}{V_{i n}^{2}} \frac{V_{b}-V_{i n}}{V_{b}}\right) R_{d s, M 1} \\
P_{c o n d, D 1}=\frac{P_{o} V_{o n, D 1}}{V_{b}}
\end{gathered}
$$

where $R_{d s, M 1}$ is the on-resistance of $M_{1}$. Therefore, the total device loss of the boost converter is as follows:

$$
P_{\text {Boost }}=P_{o n, M 1}+P_{o f f, M 1}+P_{C}+P_{c o n, M 1}+P_{c o n, D 1} .
$$

- LLC stage loss analysis

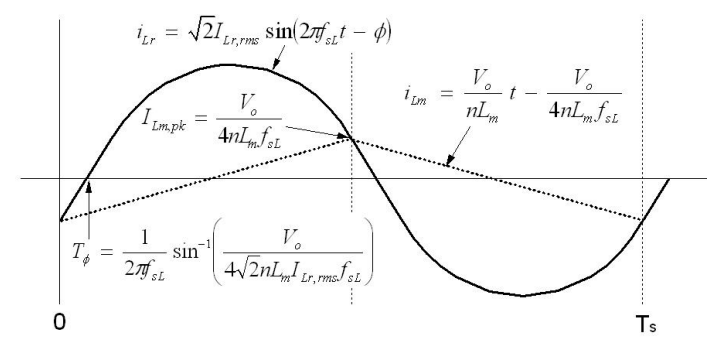

Fig. 12. Resonant current waveform and its key expressions.

Before the loss analysis is carried out, it is necessary to determine $L_{m}$ to achieve the soft-switching condition. Assuming that the reverse recovery time of the output rectifier is negligible, the equivalent circuit during the dead-time $T_{\text {dead }}$ can be depicted as in Fig. 10. To achieve the ZVS condition when $f_{s L}=f_{r}$, the peak magnetizing current $I_{L m, p k}$ should be large enough to discharge the output capacitances of the MOSFETs and the junction capacitances of the output rectifiers $D_{2} \sim D_{5}$ during $T_{\text {dead }}$. This condition gives the design guideline of $L_{m}$, and it is written as:

$$
L_{m} \leq \frac{V_{o} T_{\text {dead }}}{4 n\left(2 C_{d s, M L}+4 n^{2} C_{j, D L}\right) V_{b} f_{s L}}
$$

where $C_{j, D L}$ is the junction capacitance of each diode in the output rectifier and $C_{d s, M L}$ is the drain-source capacitance of $M_{2}$ or $M_{3}$. Eq. (18) guarantees the ZVS condition of the switches and the loss analysis is performed with the assumption that $L_{m}$ is designed to meet this inequality. Fig. 11 depicts the switching waveform of an unregulated LLC converter. When $M_{2}$ enters the turn-off transition, it experiences the linear operation region while the gate pulse passes through the Miller plateau level and $V_{d s 2}$ is linearly increased. Because the slope of $V_{d s 2}$ determines that of $V_{d s 3}$, the discharging current of the drain-source capacitance of $M_{3}$ can be calculated as:

$$
I_{M 3}=-C_{d s, M L} \frac{V_{b}}{T_{o f f, L}} .
$$

The turn-off time of $M_{2} T_{o f f, L}$ can be calculated with eq. (12). Therefore, the current flowing through the channel of 
$M_{2}$ can be obtained as:

$$
I_{M 2}=I_{L r}+I_{M 3}=I_{L m, p k}+I_{M 3}=\frac{V_{o}}{4 n L_{m} f_{s L}}-C_{d s, M L} \frac{V_{b}}{T_{o f f, L}} .
$$

With this equation, the switching loss of $M_{2}$ can be written as eq. (21) by assuming that $i_{L r}$ is linearly decreased during the dead-time.

$$
P_{o f f, M 2}=\frac{1}{6} V_{b}\left(\frac{V_{o}}{4 n L_{m} f_{s L}}-C_{d s, M L} \frac{V_{b}}{T_{o f f, L}}\right) T_{o f f, L} f_{s L} .
$$

The same turn-off loss happens at $M_{3}$, and so the total turnoff loss of the MOSFETs can be found as follows:

$$
P_{o f f, S W}=\frac{1}{3} V_{b}\left(\frac{V_{o}}{4 n L_{m} f_{s L}}-C_{d s, M L} \frac{V_{b}}{T_{o f f, L}}\right) T_{o f f, L} f_{s L}
$$

Because $M_{2}$ and $M_{3}$ exhibit the ZVS operation, eq. (22) produces the total switching loss of the MOSFETs. Fig. 12 is the resonant current waveform and its key expressions. The difference between the resonant current and the magnetizing current is transferred to the load and it can be expressed as:

$$
\frac{2 f_{s L}}{n} \int_{0}^{1 /\left(2 f_{s L}\right)}\left(i_{L r}-i_{m}\right) d t=\frac{V_{o}}{R_{o}} .
$$

With eq. (23) and the expressions of $i_{L r}$ and $i_{L m}$ in Fig. 12, the RMS value of the resonant current can be obtained as follows:

$$
I_{L r, r m s}=\frac{2 P_{o}}{V_{b}} \sqrt{\frac{R_{o}^{2}}{32 n^{4} L_{m}^{2} f_{s L}^{2}}+\frac{\pi^{2}}{8}} .
$$

Accordingly, the total conduction loss of $M_{2}$ and $M_{3}$ can be calculated as:

$$
P_{c o n, S W}=\left(\frac{2 P_{o}}{V_{b}} \sqrt{\frac{R_{o}^{2}}{32 n^{4} L_{m}^{2} f_{s L}^{2}}+\frac{\pi^{2}}{8}}\right)^{2} R_{d s, M L}
$$

where $R_{d s, M L}$ is the on-resistance of $M_{2}$ or $M_{3}$. Because the output rectifier has only a conduction loss due to the ZVZCS operation, its loss expression can be written as eq. (26).

$$
P_{\text {con }, R E C}=\frac{2 P_{o}}{V_{o}} V_{o n, D L}
$$

where $V_{o n, D L}$ is the on-drop voltage of each diode in the output rectifier. Therefore, the total device loss of the LLC converter is:

$$
P_{\text {loss }, L L C}=P_{o f f, S W}+P_{c o n, S W}+P_{c o n, R E C} .
$$

The loss equations to select the link voltage are rearranged in Table II. Performing the partial derivative of these loss equations with respect to $V_{b}$, the optimal link voltage $V_{b, o p t}$ can be obtained with the selected device parameters. Based on the calculated value of $V_{b, o p t}$ some adjustment should be performed considering the device voltage-ratings and the power losses.
TABLE III

NEXA POWER MODULE

\begin{tabular}{|c|c|}
\hline Rated net power & $1200[\mathrm{~W}]$ \\
\hline DC voltage range & $25 \sim 50[\mathrm{~V}]$ \\
\hline DC current range & $0 \sim 48[\mathrm{~A}]$ \\
\hline Rated DC voltage & $26[\mathrm{~V}]$ \\
\hline Rated DC current & $46[\mathrm{~A}]$ \\
\hline
\end{tabular}

TABLE IV

OPERATION SCENARIO FOR COMPUTER SIMULATION

\begin{tabular}{|c|c|c|c|c|c|c|c|c|}
\hline $\begin{array}{c}\text { Time } \\
{[\mathrm{s}]}\end{array}$ & 1 (1) & 2 (2) & 3 (3) & 4 (4) & 5 & 6 & 7 & 8 \\
\hline $\begin{array}{c}\mathrm{P} \\
{[\mathrm{W}]}\end{array}$ & 100 & 300 & 500 & 1000 & 1000 & 500 & 300 & 100 \\
\hline $\begin{array}{c}\mathrm{Q} \\
{[\text { Var }]}\end{array}$ & 0 & 300 & 100 & 0 & 0 & 300 & 100 & 0 \\
\hline
\end{tabular}

\section{Computer Simulation}

In order to analyze the operation of the proposed fuel-cell power conditioning system, first the modeling of the fuel-cell was carried out. The electrical characteristics of the unit fuelcell is represented by a mathematical model described in [1]. Since the unit cell has a low output voltage and a small current rating, many unit cells are connected in series to form a stack structure so as to build up a reasonable terminal voltage. The voltage rating of the stack is determined by multiplying the unit cell voltage by the number of cells, while the current rating is determined by multiplying the unit cell current density by the cell area.

Table III shows the characteristic data for a commercial fuel cell stack, called a Nexa Power Module. The terminal voltage of the fuel cell stack is about $50 \mathrm{~V}$ under the no load condition, while it is $26 \mathrm{~V}$ under the full load condition.

Many computer simulations were carried out with PSCAD/EMTDC software to verify the operation of the proposed power conditioning system. The simulation model consists of a fuel-cell stack model, a 2-stage DC-DC converter, a grid-tied inverter, and a digital controller. The fuel-cell stack model and the digital controller were represented by user-defined models programmed in $\mathrm{C}$-code, while the 2stage DC-DC converter, the grid-tied inverter, and the 3-phase voltage source were represented by built-in models in the PSCAD/EMTDC software.

In order to confirm the voltage and current variations of the fuel cell according to the variation in the active power, a simulation scenario was selected as shown in Table IV. The active power varies in a step manner from $100 \mathrm{~W}$ up to $1 \mathrm{~kW}$, and then down to $100 \mathrm{~W}$, while the reactive power varies from 0 up to 300Var, and then down to 0Var during $0 \sim 8 \mathrm{sec}$.

Fig. 13 shows the simulation results to verify the operation of the proposed system. Fig. 13(a) shows the operation voltage of the fuel cell, which changes according to the variation in the active power delivered to the grid.

Fig. 13(b) shows the operation current of the fuel cell, which changes according to the variation in the active power delivered to the grid similar to the case of the voltage variation.

Fig. 13(c) shows the tracking performance of the active power. It is clear that the transient phenomena can be stabilized within $1 \mathrm{sec}$ and that the steady-state tracking performance seems to be accurate. Fig. 13(d) shows the tracking performance of the reactive power. It is clear that the measured value 


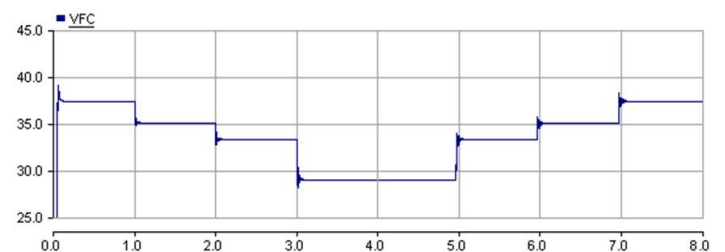

(a) Fuel-cell Operation Voltage.

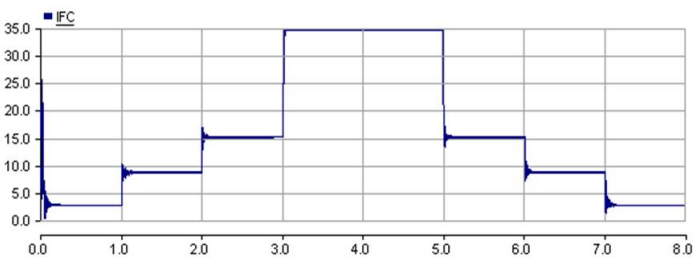

(b) Fuel-cell Operation Current.

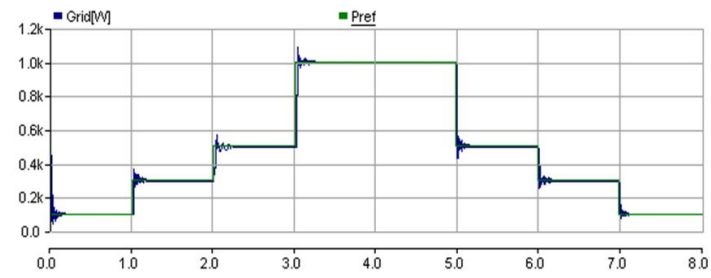

(c) Active-Power Control.

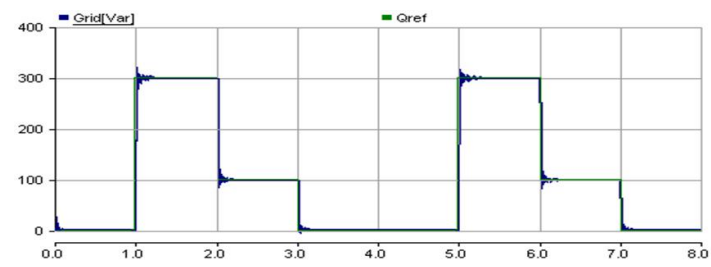

(d) Reactive-Power Control.

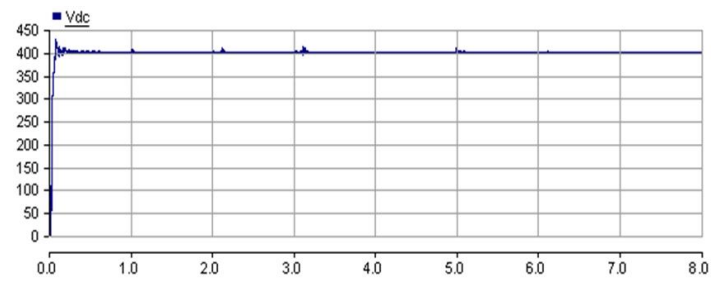

(e) DC Output Voltage Control.

Fig. 13. Simulation results of proposed system.

of the reactive power tracks the reference value accurately and that the transient phenomena is not so severe. Fig. 13(e) shows the tracking performance of the DC output voltage. The DC output voltage is maintained at $400 \mathrm{~V}$ without severe transients.

\section{EXPERIMENTAL WORK}

A prototype of the proposed system was built and tested to confirm the feasibility of the hardware implementation as shown in Fig. 14. The fuel-cell power unit used in the experiment is a $1.2 \mathrm{~kW}$ Ballard Nexa PEM Module. It has a monitoring system with a PC, which monitors the operation status of the fuel cell module through a communication link.

The 2-stage DC-DC converter was mounted on a rack together with the 3-phase inverter. The controller for the 2stage DC-DC converter was designed and built with OP amps.

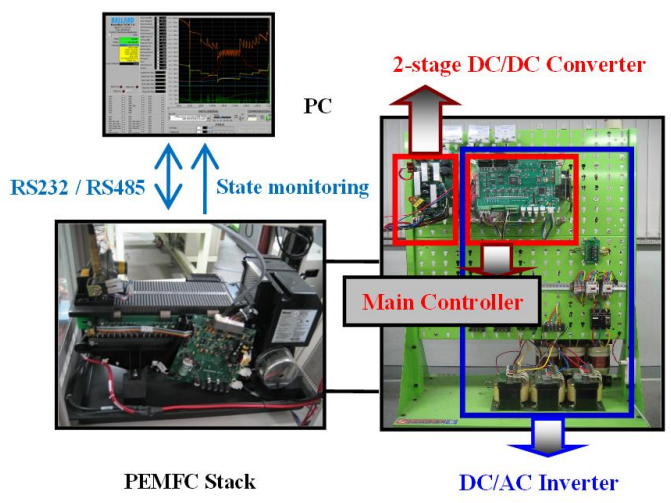

Fig. 14. Experiment Set-Up of Prototype.

TABLE V

OPERATION SCENARIO FOR HARDWARE EXPERIMENT

\begin{tabular}{|c|c|c|c|c|c|c|c|c|}
\hline $\begin{array}{c}\text { Time } \\
{[\mathrm{s}]}\end{array}$ & 100 & 200 & 300 & 400 & 500 & 600 & 700 & 800 \\
\hline $\begin{array}{c}\mathrm{P} \\
{[\mathrm{W}]}\end{array}$ & 100 & 300 & 500 & 1000 & 1000 & 500 & 300 & 100 \\
\hline $\begin{array}{c}\mathrm{Q} \\
{[\text { Var }]}\end{array}$ & 0 & 300 & 100 & 0 & 0 & 300 & 100 & 0 \\
\hline
\end{tabular}

It adjusts the duty ratio of the 2-stage DC-DC converter to boosts the output voltage up to $400 \mathrm{~V}$. The boost converter stage was designed to operate with $30 \mathrm{kHz}$ of switching frequency and the LLC stage was designed to operate with $100 \mathrm{kHz}$ of switching frequency.

The controller for the grid-tied inverter was designed and built with a floating-point TMS320vc33-150 DSP and a EP1K100QC208 EPLD (Erasable Programmable Logic Device). The control board has $24 \mathrm{ch}$ of ADC, $4 \mathrm{ch}$ of DAC, $4 \mathrm{ch}$ of Digital Input, 4ch of Digital Output, 1module of Encoder pulse input, 1port of RS232, and 2ports of RS485.

The actual fuel-cell stack can not track the fast variation of the active power in the grid because the chemical reaction in the fuel cell stack is relatively much slower. In order to confirm safe and reliable operation, the duration of the active power variation was determined by $100 \mathrm{sec}$ in an actual experiment. A simulation scenario was selected as shown in Table V.

Fig. 15 shows the experimental results to verify the operation of the proposed system. Fig. 15(a) shows the operation voltage and current of a fuel cell module with $10 \mathrm{~V}(\mathrm{~A}) / \mathrm{div}$. The time div was selected to be $100 \mathrm{~s}$, which is the same as the duration period of the active or reactive power. As the active power increases, the fuel cell voltage decreases while the fuel cell current increases. Fig. 15(b) shows that the measured active power tracks the reference value accurately without a severe transient.

Fig. 15(c) shows the output voltage and current variation of the fuel cell. The output current has the same variations as the active power while the capacitor voltage is maintained at $400 \mathrm{~V}$. This confirms that the DC-DC converter can accurately control the output voltage without a variation in the active power. Fig. 15(d) shows that the measured reactive power tracks the reference value accurately without a severe transient.

Fig. 16 shows the voltage-current characteristic curve for the fuel cell module used in the experiment. The no-load voltage of the fuel cell is about $50 \mathrm{~V}$ and the terminal voltage goes 


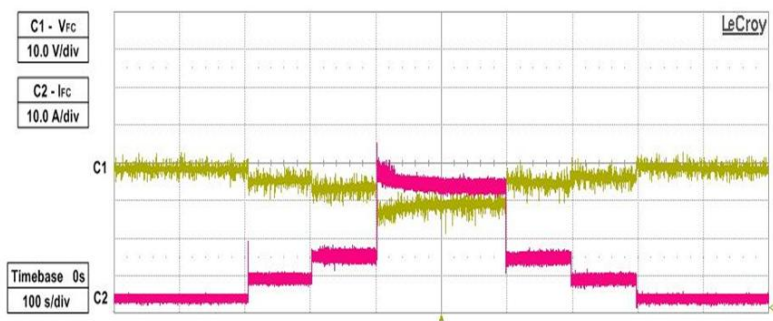

(a) Fuel-Cell Operation Voltage and Current.

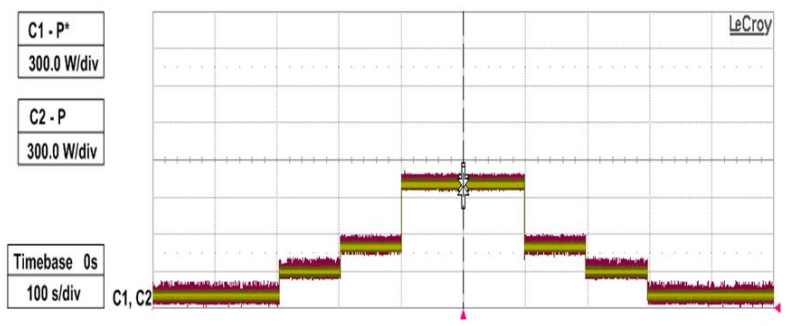

(b) Active-Power Control.

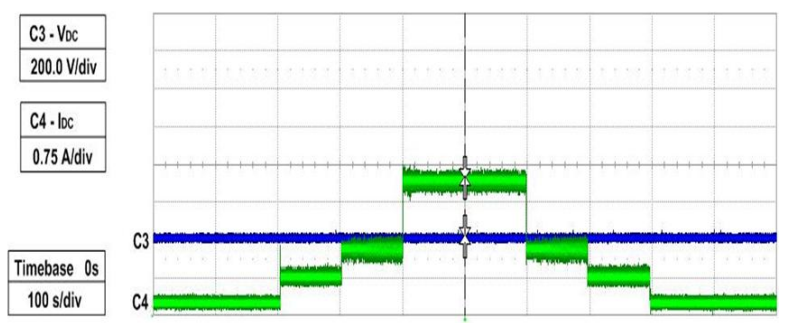

(c) DC Output Voltage and Current.

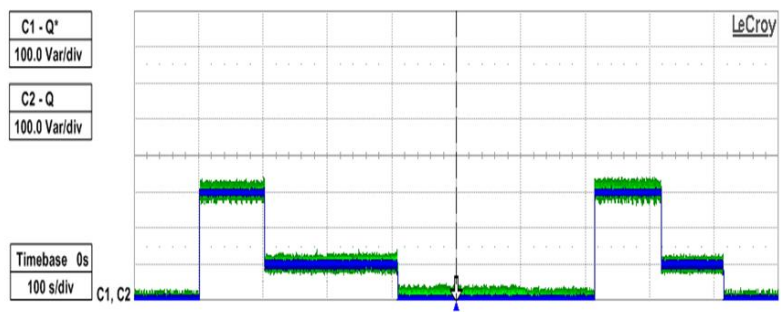

(d) Reactive-Power Control.

Fig. 15. Experimental Results of Hardware Prototype.

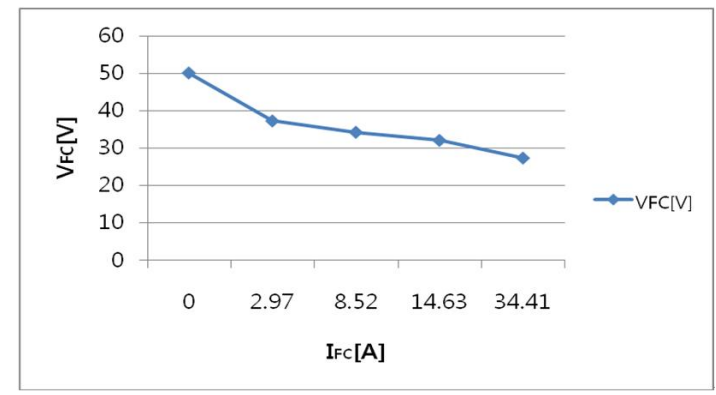

Fig. 16. Measured Fuel Cell Voltage and Current.

down while the output current increases and the active power increases. At an active power of $1 \mathrm{~kW}$, the fuel cell voltage is $27.3 \mathrm{~V}$, and the fuel cell current is $34.41 \mathrm{~A}$.

Fig. 17 shows the efficiency of the 2-stage DC-DC converter which was measured through experimentation. The efficiency was measured with respect to the lowest input voltage of

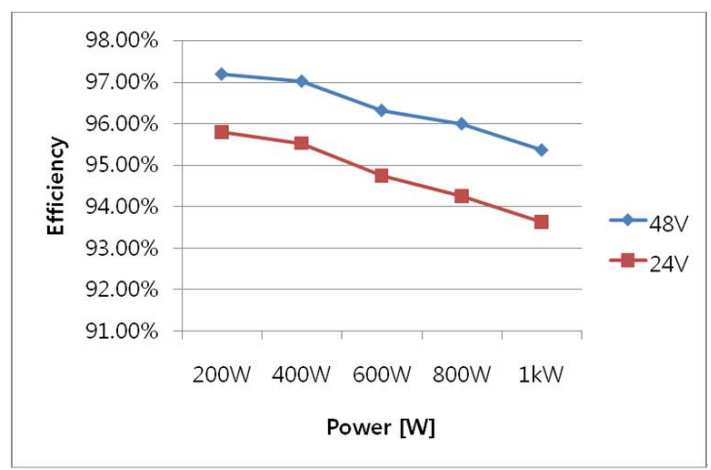

Fig. 17. Measured Efficiency of 2-Stage DC-DC Converter.

$24 \mathrm{~V}$ and the highest input voltage of $48 \mathrm{~V}$. The efficiency of the proposed converter is $93.5 \%$ when the input voltage is $24 \mathrm{~V}$ and the output power is $1 \mathrm{~kW}$. Since the actual fuel cell voltage is $27.4 \mathrm{~V}$ at an output of $1 \mathrm{~kW}$, it can be confirmed that the efficiency of the DC-DC converter is approximately $94 \%$. Assuming that the efficiency of the grid-tied inverter is $97 \%$, the total efficiency of the proposed power conditioning system could be about $91 \%$.

\section{CONCLUSION}

This paper proposes a new grid-tied power conditioning system for fuel cell power generation. The proposed power conditioning system consists of a 2-stage DC-DC converter and a 3-phase inverter.

The 2-stage DC-DC converter is composed of a hardswitching boost converter cascaded with an unregulated LLC resonant converter. The fuel cell output voltage of $26-48 \mathrm{~V}$ is boosted up to $80 \mathrm{~V}$ by controlling the duty ratio of the hard-switching boost converter. The half-bridge LLC resonant converter boosts the input voltage of $80 \mathrm{~V}$ up to $400 \mathrm{~V}$ by operating a fixed duty ratio.

The operation of the proposed power conditioning system was verified through simulations with PSCAD/EMTDC software by checking the active and reactive power control capability. Based on the simulation results, a laboratory experimental set-up was built with a $1.2 \mathrm{~kW}$ PEM fuel-cell stack to verify the feasibility of the hardware implementation.

The developed power conditioning system shows a high efficiency of $91 \%$, which is very positive for commercialization. It can be used for implementing a micro-grid with fuel cell power generation.

\section{ACKNOWLEDGMENT}

The work was supported by a National Research Foundation of Korea Grant funded by the Korea Government (MEST), (NRF-2010-R1A5A003-2010-0026283).

\section{REFERENCES}

[1] B. Yang, F. C. Lee, A. J. Zhang, and G. Huang, "LLC resonant converter for front end DC/DC conversion," in Proc. APEC, Vol. 2, pp. 1108-1112, 2002.

[2] T.-W. Lee, S.-H. Kim, Y.-H. Yoon, S.-J. Jang, and C.-Y. Won, "A 3 $\mathrm{kW}$ fuel cell generation system using the fuel cell simulator," in Proc. Industrial Electronics, Vol. 2, pp. 833-837, 2004. 
[3] B. Bouneb, D. M. Grant, A. Cruden, and J. R. McDonald, "Grid connected inverter suitable for economic residential fuel cell operation," in Proc. EPE, p. 10, 2005.

[4] P. J. H. Wingelaar, J. L. Duarte, and M. A. M. Hendrix, "Dynamic characteristics of PEM fuel cells," in Proc. PESC, pp. 1635-1641, 2005.

[5] C. Wang and M. H. Nehrir, "Distributed generation applications of fuel cells," in Proc. Power Systems Conference, pp. 244-248, 2006.

[6] D. Polenov, H. Mehlich, and J. Lutz, "Requirements for MOSFETs in fuel cell power conditioning applications," in Proc. EPE-PEMC, pp. 1974-1979, 2006.

[7] A. K. Rathore, A. K. S. Bhat, and R. Oruganti, "A comparison of softswitched DC-DC converters for fuel cell to utility interface application," in Proc. PCC, pp. 588-594, 2007.

[8] A. Mousavi, P. Das, and G. Moschopoulos, "A ZCS-PWM full-bridge boost converter for fuel-cell applications," in Proc. APEC, pp. 459-464, 2009.

[9] X. Yu, M. R. Starke, L. M. Tolbert, and B. Ozpineci, "Fuel cell power conditioning for electric power applications: a summary," in Proc. IET, Vol. 1, No. 5, pp. 643-656, 2007.

[10] S.-Y. Park, C.-L. Chen, and J.-S. Lai, "Wide range active and reactive power flow controller for a solid oxide fuel cell power conditioning system," in Proc. APEC, pp. 952-958, 2008.

[11] J.-M. Kwon, E.-H. Kim, B.-H. Kwon, and K.-H. Nam, "High-efficiency fuel cell power conditioning system with input current ripple reduction," IEEE Trans. Ind. Electron., Vol. 56, No. 3, pp. 826-834, Mar. 2009.

[12] G. Hoogers, FUEL CELL TECHNOLOGY HANDBOOK, CRC Press, 2003.

[13] Texas Instrument Seminal Topics Slup170 - Estimating MOSFET parameters from the datasheet - http//focus.ti.com/lit/ml/slup170.pdf, 2002.

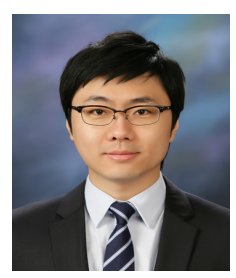

Jong-Kyou Jeong received his B.S. and M.S. in Electrical Engineering from Myongji University, Korea, in 2008 and 2010, respectively. He is currently working towards his Ph.D. at Myongji University. His current research interests include power electronic applications for custom power and distributed generation.

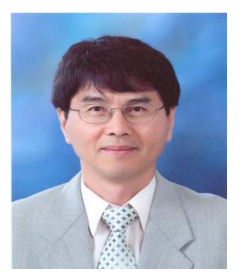

Byung-Moon Han (S'91-M'92-SM'00) received his B.S. in Electrical Engineering from Seoul National University, Korea, in 1976, and his M. S. and Ph.D. from Arizona State University in 1988 and 1992, respectively. He was with the Westinghouse Electric Corporation as a Senior Research Engineer in the Science and Technology Center. Currently he is a Professor in the Department of Electrical Engineering at Myongji University, Korea. His current research interests include power electronics applications for FACTS devices, custom power, and distributed generation.

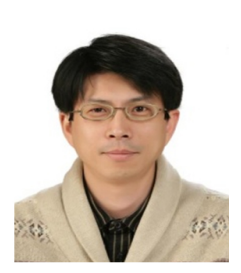

Jun-Young Lee received his B.S. in Electrical Engineering from Korea University, CitySeoul, in 1993, and his M.S. and Ph.D. in Electrical Engineering from the Korea Advanced Institute of Science and Technology (KAIST), Taejon, Korea, in 1996 and 2001, respectively. Begining in 2001, he worked for four years as a Manager in the Plasma Display Panel Development Group, Samsung SDI where he was involved in circuit and product development. In 2005, he joined the School of Electronics and Computer Engineering, Dankook University, Chungnam, Korea, as a Senior Lecturer. His current research interests are in the areas of power electronics which include ac/dc power factor correction, converter topology design, converter modeling, soft switching techniques, display driving systems and liquid crystal display backlight units.

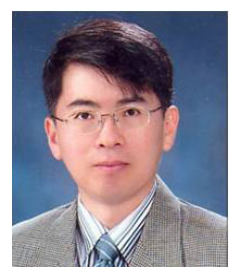

Nam-Sup Choi received his B.S. in Electrical Engineering from Korea University, Seoul, South Korea, in 1987. He received his M.S. and Ph.D. in Electrical Engineering from the Korean Advanced Institute of Science and Technology (KAIST), Taejon, South Korea, in 1989 and 1994, respectively. He is currently a Professor in the Division of Electrical Electronic Communication and Computer Engineering, Chonnam National University, Yeosu, South Korea. His current research interests include the modeling and control of power converters and systems. 